\title{
Marine mammal response to interannual variability in Monterey Bay, California
}

\author{
Julia A. Burrows ${ }^{1,2, *}$, James T. Harvey ${ }^{1}$, Kelly M. Newton ${ }^{3}$, Donald A. Croll ${ }^{3}$, \\ Scott R. Benson ${ }^{4}$ \\ ${ }^{1}$ Moss Landing Marine Laboratories, 8272 Moss Landing Rd., Moss Landing, California 95039, USA \\ ${ }^{2}$ Present address: Duke University Marine Laboratory, 135 Duke Marine Lab Rd., Beaufort, North Carolina 28516, USA \\ ${ }^{3}$ Center for Ocean Health, University of California Santa Cruz, 100 Shaffer Rd., Santa Cruz, California 95060, USA \\ ${ }^{4}$ Protected Resources Division, Southwest Fisheries Science Center, National Marine Fisheries Service, \\ National Oceanic and Atmospheric Administration c/o Moss Landing Marine Laboratories Norte 7544 Sandholdt Road, \\ Moss Landing, California 95039, USA
}

\begin{abstract}
The coastal upwelling ecosystem near Monterey Bay, California, is a productive yet variable ecosystem and an important foraging area for many mobile apex predators, such as marine mammals. Long-term studies are necessary to better understand how wide-ranging predators respond to temporal environmental variability; however, few of these studies exist. We conducted monthly shipboard line-transect surveys in Monterey Bay from 1997 to 2007. We identified 22 species of marine mammals, and calculated monthly and annual densities for the 12 most commonly sighted (focal) species. Species richness remained relatively constant (mean richness $\pm \mathrm{SE}: 13.7 \pm 0.396$ species $\mathrm{yr}^{-1}$ ) from 1997 to 2006 . Focal species were most evenly distributed (Shannon's equitability, $E_{\mathrm{H}}=0.820$ ) but least dense (mean density \pm SE: $0.0598 \pm 0.0141$ ) during the anomalous upwelling conditions of 2005, and least even $\left(1997 E_{\mathrm{H}}=0.413 ; 1998 E_{\mathrm{H}}=0.407\right)$ but dense (mean density \pm SE: 1997: $0.433 \pm 0.177 ; 1998: 0.438 \pm 0.169$ ind $\mathrm{km}^{-2}$ ) during the 1997/1998 El Niño event. There were no statistically significant differences in the densities of marine mammal species between warmer and cooler years. The community and species-specific responses of marine mammals to warm-water years differed depending on the mechanism of oceanographic variability. During the 1997/1998 El Niño (a basin-wide event), marine mammals aggregated in nearshore areas, such as Monterey Bay, with relatively greater productivity than offshore regions, whereas during anomalous upwelling conditions of 2005 (a more localized oceanographic event), marine mammals redistributed away from Monterey Bay to areas less affected by the anomaly.
\end{abstract}

KEY WORDS: Upwelling $\cdot$ El Niño $\cdot$ Density $\cdot$ Diversity $\cdot$ California Current $\cdot$ Distance sampling

\section{INTRODUCTION}

Eastern boundary currents, such as the California Current, are among the most productive ecosystems in the world (Hickey 1979, Glantz \& Thompson 1981). Productivity is driven locally by coastal upwelling (Barber \& Smith 1981, Carr \& Kearns 2003) and on a larger scale by oceanic circulation patterns. Seasonal upwelling in the California Current is initiated when northwest winds along the west coast of North
America combine with the earth's rotation to create offshore Ekman transport of surface waters, resulting in the movement of cool, nutrient-rich waters to the surface (Barber \& Smith 1981, Huyer 1983, Service et al. 1998). Nutrients brought to the euphotic zone induce phytoplankton blooms, which increase productivity at multiple trophic levels (Hutchings et al. 1995, Pennington \& Chavez 2000).

In addition to seasonal coastal upwelling, interannual variability resulting from El Niño or La Niña 
events influences productivity in the California Current (Barber \& Chavez 1983, Chavez et al. 2002). El Niño events are typically associated with a delayed and shortened upwelling season (Bograd et al. 2009), increased sea surface temperatures (SSTs), a deepening of the thermocline, reduced nutrient availability, and decreased primary production (Barber \& Chavez 1983, Hayward 1993, Lenarz et al. 1995, Chavez 1996, Chavez et al. 2002, Marinovic et al. 2002). La Niña events often follow El Niño's and result in a cooler, more productive environment (Chavez et al. 2002, Marinovic et al. 2002).

Physical and biological oceanographic variables associated with upwelling and El Niño or La Niña events influence the density and diversity of apex predators, such as marine mammals (Sydeman \& Allen 1999, Benson et al. 2002, Burtenshaw et al. 2004, Keiper et al. 2005, Lowry \& Forney 2005). Researchers have reported increased species diversity and richness in the North Pacific during El Niño years, and attributed the increases to the northward movement of species typically associated with warmer waters (Benson et al. 2002, Worm et al. 2005, Hooff \& Peterson 2006). Indeed marine mammal species richness patterns are most closely correlated with SST (Whitehead et al. 2010) and the trend of increased biodiversity in lower (tropical) latitudes is a well-documented phenomenon (Rohde 1992, Hillebrand 2004). For example, copepod communities were most diverse and evenly distributed in warm tropical and subtropical waters (Woodd-Walker et al. 2002). Organisms that traditionally reside in warmer, lower-latitude habitats appear to be expanding their range poleward as the world's oceans warm, resulting in an observed (and anticipated) increase in biodiversity at higher latitudes (Hughes 2000, Beaugrand et al. 2002, Hyrenbach \& Veit 2003, Whitehead et al. 2008). The response of these species to shortterm variability, such as delayed and weakened seasonal upwelling (Snyder et al. 2003) or El Niño events, may be the best predictor of how these species will respond to long-term oceanographic change, such as ocean warming (Trathan et al. 2007). Understanding how environmental variability affects species density and diversity is an important step in anticipating changes that may occur in species composition and ecosystem functioning over longer time periods.

Many researchers have studied the movements or distribution of marine mammal species throughout a season or for several years (Sydeman \& Allen 1999, Friedlaender et al. 2006, Weise et al. 2006), but few long-term (decadal) studies exist. Our objective was to examine species-specific and community responses of marine mammals to interannual environmental variability. To accomplish this objective, we (1) documented changes in marine mammal density and diversity in Monterey Bay, California, throughout an 11-yr period (1997-2007) and (2) tested for differences in marine mammal density and diversity (richness and evenness) between years with warm and cool oceanic conditions. We expected that marine mammal species typically associated with cool waters would be present in greater densities during years dominated by cool oceanic conditions (strong upwelling, low SSTs), species typically associated with warm waters would be present in greater densities during years dominated by warm oceanic conditions (weak upwelling, high SSTs), and that there would be no significant differences in the densities of resident species in Monterey Bay during warm and cool years. We also expected greater marine mammal species richness (the number of different species present) and evenness (the relative abundances of each species present) in Monterey Bay during warm-water years as species associated with warm waters moved north into the bay, but regularly occurring species remained.

\section{MATERIALS AND METHODS}

\section{Study area}

Monterey Bay, located off the central California coast, is the largest bay $\left(\sim 1200 \mathrm{~km}^{2}\right)$ on the west coast of the United States completely open to the ocean (Benson et al. 2002, Croll et al. 2005; Fig. 1). The Monterey Submarine Canyon, one of the largest canyons in the world (Shepard 1973), divides the bay into 2 nearly equal shallower shelves (up to $140 \mathrm{~m}$ deep and 10 to $15 \mathrm{~km}$ wide), with deeper waters over the canyon in the center of the bay (Greene et al. 2002; Fig. 1). Monterey Bay is influenced seasonally by a coastal upwelling plume that originates $\sim 30 \mathrm{~km}$ to the north, near Point Año Nuevo (Rosenfeld et al. 1994). Upwelling winds off the central California coast usually begin in March and continue through August, with periods of wind relaxation (Send et al. 1987) becoming more frequent during July and August (Pennington \& Chavez 2000). A short transitional oceanic period occurs from late August through November, when winds continue to relax and SSTs increase until a warmer, less productive winter Davidson Current season begins in December and persists through February (Skogsberg 1936, Skogsberg \& Phelps 1946, Pennington \& Chavez 2000). 


\section{Line transect field methods}

Monterey Bay was divided into 7 transect lines that were surveyed for marine mammals throughout the 11-yr study (Benson et al. 2002, Croll et al. 2005; Fig.1). Transect lines were 10 to $25 \mathrm{~km}$ in length, and totaled $\sim 126 \mathrm{~km}$. The location of the first line was randomly chosen from a 3-min latitudinal range, after which each line was spaced $5.5 \mathrm{~km}$ apart for uniform coverage of the bay (Benson et al. 2002). From September 2006 until November 2007, the first line was no longer randomly selected and the same grid of 7 lines was surveyed. The entire survey area, 909 $\mathrm{km}^{2}$, included all of Monterey Bay and the waters off the Monterey Peninsula (except nearshore regions) beginning at the $55 \mathrm{~m}$ (30 fathom) isobath and extending WNW to $122.083^{\circ} \mathrm{W}$ longitude (Fig. 1). Surveys were completed during 2 consecutive days each month from May through November 1997 to 2006 at a ship speed of $18.5 \mathrm{~km} \mathrm{~h}^{-1}$ (10 knots). Additional surveys were completed during 2 consecutive days in January and March 2003 to 2006. Surveys

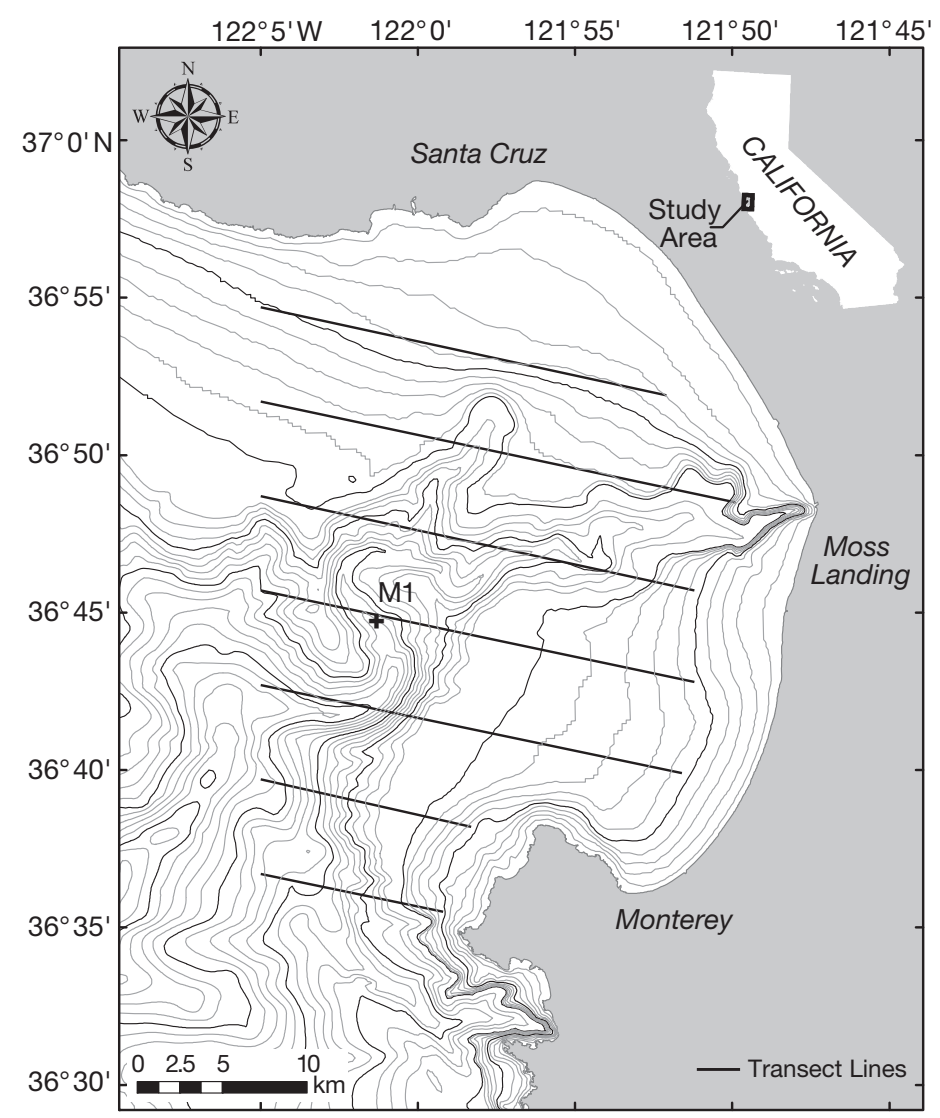

Fig. 1. Monterey Bay study area with marked transect lines. M1: location of oceanographic sampling mooring. Bathymetric contour lines are shown for $10 \mathrm{~m}$ depth increments were conducted 1 day a month (5 transect lines totaling $82 \mathrm{~km}$ ) during January, March, May, July, August, and November 2007.

Two observers stationed on top of the bridge $(4.3 \mathrm{~m}$ above sea level, except for March and July 2007 when observers were $5.66 \mathrm{~m}$ above sea level) searched for marine mammals on each side of the vessel from the trackline to $90^{\circ}$ abeam of the ship using Fujinon $7 \times 50$ binoculars with a compass and reticle scale in the oculars. A third center observer searched mainly with the naked eye along the trackline and near the ship (binoculars were used to aid in species identification), while a fourth person entered sightings into a laptop computer using the program SeeBird_WinCruz (Holland 2008) with direct input from the ship's GPS. When a sighting occurred, all observers assisted with species identification (to the lowest taxonomic level) and abundance estimation. Time, latitude, longitude, species, number of individuals, cue (body, blow), method of detection (eye, binoculars), compass bearing, and number of reticle marks down from the horizon were recorded. Environmental conditions (fog or rain, visibility, wind direction and speed, swell direction and speed, horizontal and vertical sun position, and Beaufort sea state) were continually updated throughout the survey.

\section{Density calculations}

Radial distances of marine mammal groups to the trackline were obtained using binocular reticle measurements and the platform (observer eye) height using the formula of Lerczak \& Hobbs (1998). Radial distances for sightings made using the land/ocean interface as a reticle reference rather than the true horizon (sky/ocean) were adjusted using the military analyst toolset in ArcMap (ArcGIS desktop version 9.2, ESRI). Perpendicular distance $(x)$ was computed from the radial distance $(r)$ and the angle $(\theta)$ between the trackline and the marine mammal group using trigonometry $(x=r \sin \theta)$.

Monthly marine mammal densities were calculated from line transect data using the Multiple Covariate Distance Sampling (MCDS) analysis engine in Distance software (Buckland et al. 2001, Buckland et al. 2004, Thomas et al. 2006). Density calculations were based on Eq. (1):

$$
\hat{D}=\frac{\sum_{i=1}^{n} s_{i} / \hat{p}_{i}}{2 w L}
$$


where $\hat{D}$ is the density estimate (ind. $\mathrm{km}^{-2}$ ), $n$ is the number of marine mammal groups detected (where a group is comprised of one or more individuals), $s_{i}$ is the size of the $i$ th group, $w$ is the truncation distance and half-width of the transect, $L$ is the total line length, and $\hat{p}_{i}$ is the estimated probability of detecting the ith group (Buckland et al. 2001, 2004). Detection probability $\left(\hat{p}_{i}\right)$ was estimated from the detection function $(g(x)=$ the probability of detecting a group, given that it is at distance $x$ from the line), which was fitted to the perpendicular distances using Distance software. Sightings from May through November 1997 to 2007, and January and March 2003 to 2007 were used to obtain the detection function. A sequence of models with different sets of covariates and series expansion terms (cosine, simple or hermite polynomial) were used to find the best fit model (i.e. detection function), which minimized Akaike's information criterion (AIC; Akaike 1973). Only statistically non-collinear covariates with a significant effect on perpendicular distance were considered as covariates in MCDS (Beaufort sea state, swell height, group size, and visibility). Visibility was the approximated distance to the horizon $(\leq 6.44 \mathrm{~km})$ and was affected by fog and haze. Only survey effort that occurred in acceptable Beaufort sea states (0 to 4) and swell heights $(<2.4 \mathrm{~m})$ were included in analyses. Additionally, Beaufort sea state was treated as a factor with discrete levels 0 to 4 , whereas all other covariates were continuous variables (non-factors). Observer was not included as a covariate because there were more than 200 volunteer observers during the 11-yr study. Because more experienced observers were likely better at detecting marine mammals than less experienced observers, not including observer as a covariate added to the random error in the density estimates. The truncation distance was set for each species such that $\sim 5 \%$ of the most distant sightings were excluded (Buckland et al. 2001).

Model convergence was more difficult to achieve using all combinations of covariates and adjustments (i.e. too many parameters) for species with fewer sightings. In these cases, the best model was chosen from models including only one covariate and no adjustments, or no covariates (null model). Additionally, to achieve model convergence using the hazard rate key function in MCDS, starting values for the hazard rate parameter estimates were manually selected using those calculated from the half normal model for the same species, with the power parameter coefficient set to 2. Although distance sampling methods assume certain detection on the trackline (i.e. $g(0)=1$ ), it is likely that some individuals were not seen (perception bias) or submerged (availability bias) as the vessel passed, resulting in an underestimation of true density. However, because the aim of this study was to compare relative densities of animals in the same area through time, consistent underestimation should not affect the results.

\section{Annual density and diversity}

Once monthly density estimates were obtained, mean annual focal species density and individual species densities were calculated for 1997 to 2007 using monthly density estimates for May through November. Focusing on these months enabled us to document the presence of seasonal summer migrants in addition to regularly sighted resident species, and capture the time period when the region is most productive. Mean focal species density was defined as the mean annual density of the 12 most abundant species with enough sightings to obtain density estimates.

Species richness and species evenness were calculated for 1997 to 2006 (2007 was excluded from diversity calculations due to reduced effort that year). Rather than using solely a diversity index, such as the Shannon-Weiner index, diversity measurements were divided into richness and evenness to discern which variable more strongly contributed to species diversity patterns. Species richness $(S)$ was defined as the total number of marine mammal species identified each year, including rare species. Sightings that could not be identified to species were excluded from analyses. Species evenness was calculated for each year using the 12 most abundant species (focal species) with enough sightings to obtain density estimates. Species evenness was determined by first calculating the Shannon-Weiner index of diversity $(H)$ :

$$
H=-\sum_{i=1}^{s}\left(p_{i}\right)\left(\log p_{i}\right)
$$

where $p_{i}$ is the proportion of total sample belonging to the $i$ th species. Shannon's equitability ( $E_{\mathrm{H}}$, evenness) was then calculated as:

$$
E_{H}=\frac{H}{\log S}
$$

where $S$ is the annual species richness of the 12 most abundant species. Shannon's equitability index for species evenness quantifies the numerical equality of the annual densities of each of the 12 focal species. An $E_{\mathrm{H}}$ value of 1 indicates complete evenness (i.e. all 12 species were present in equal densities). Because of the difficulties associated with identifying common 
dolphins in the field, long-beaked Delphinus capensis and short-beaked Delphinus delphis common dolphins were treated as 1 species for analyses.

\section{Environmental variables}

SST and upwelling indices (UIs) were used to categorize years as warm or cool. Mean monthly SSTs $\left({ }^{\circ} \mathrm{C}\right)$ were calculated from a continuous record of temperature at $1 \mathrm{~m}$ depth using the Monterey Bay Aquarium Research Institute's (MBARI) M1 mooring (www.mbari.org/) (Fig. 1). Mean monthly UIs $\left(\mathrm{m}^{3} \mathrm{~s}^{-1}\right.$ $100 \mathrm{~m}^{-1}$; measures of wind-driven offshore Ekman transport derived from 6-hourly synoptic surface atmospheric pressure fields) from $36^{\circ} \mathrm{N}, 122^{\circ} \mathrm{W}$ were obtained from the Southwest Fisheries Science Center's (SWFSC) Environmental Research Division's (ERD) website (www.pfeg.noaa.gov/).

\section{Warm vs. cool years}

Species were classified as being associated with warm or cool waters in accordance with prior studies of marine mammal habitat associations off the US west coast (e.g. Forney \& Barlow 1998, Keiper et al. 2005, Barlow \& Forney 2007). Dall's porpoise Phocoenoides dalli, northern right whale dolphin Lissodelphis borealis, and Pacific white-sided dolphin Lagenorhynchus obliquidens typically occur in cool temperate to sub-arctic waters and were thus classified as cool-water-associated species, whereas common dolphin Delphinus spp. and Risso's dolphin Grampus griseus typically occur in tropical and warm temperate waters and were thus classified as warm-water-associated species. California sea lion Zalophus californianus, harbor porpoise Phocoena phocoena, harbor seal Phoca vitulina, and sea otter Enhydra lutris can be seen year-round off the central California coast and were classified as resident species. Blue whales Balaenoptera musculus and humpback whales Megaptera novaeangliae could not be clearly categorized as species associated with warm or cool water because they are wide-ranging predators that migrate seasonally between the tropics and higher latitudes. Blue and humpback whales are seasonal visitors to Monterey Bay, and are most abundant in the area during the summer and fall months.

To determine whether mean annual SST and UI affected annual marine mammal density and diversity, years were grouped into 2 categories based on similarities in physical oceanographic conditions: cool (low SSTs and high UIs) and warm (high SSTs and low UIs). Years with lesser UI and greater SST pairings $(1998,2004,2005$, and 2006) were categorized as warm years and years with greater UI and lesser SST pairings (1999, 2001, 2002, and 2007) were categorized as cool years (Fig. 2). Discriminate function analysis, performed using SYSTAT (version 12, SYSTAT Software), indicated that warmer and cooler year groupings were significantly different based on UIs and SSTs $(\mathrm{n}=8, F=29.847, \mathrm{p}=0.002, \alpha=0.05)$ and generated scores $(-15.863+0.626 \times \mathrm{SST}-0.864$ $\times$ UI) to categorize years without a clear grouping as warm (1997) or cool $(2000,2003)$. Warm and cool year groupings agreed with annual oceanic conditions described in the California Cooperative Oceanic Fisheries (CalCOFI) reports (www.calcofi.org/).

Two distinct oceanographic events occurred during our study, resulting in anomalously warm conditions: a strong El Niño during 1997/1998, which affected the entire Pacific Ocean basin (Chavez et al. 2002), and delayed and weakened upwelling during the spring and summer of 2005, which affected only the northern California Current (Peterson et al. 2006). The effect of these 2 events on species composition, in addition to the effect of warm and cool years on
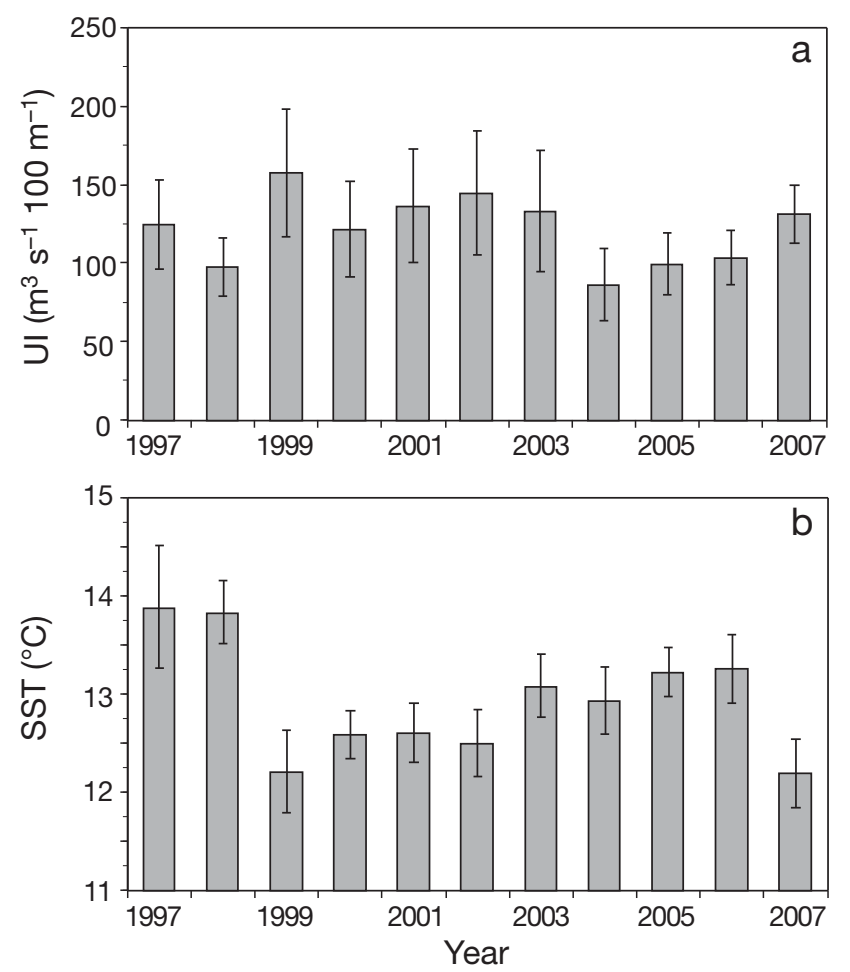

Fig. 2. (a) Upwelling indices (UIs) and (b) sea surface temperatures (SSTs) in Monterey Bay, California, January to December 1997 to 2007 . Annual means \pm SE 


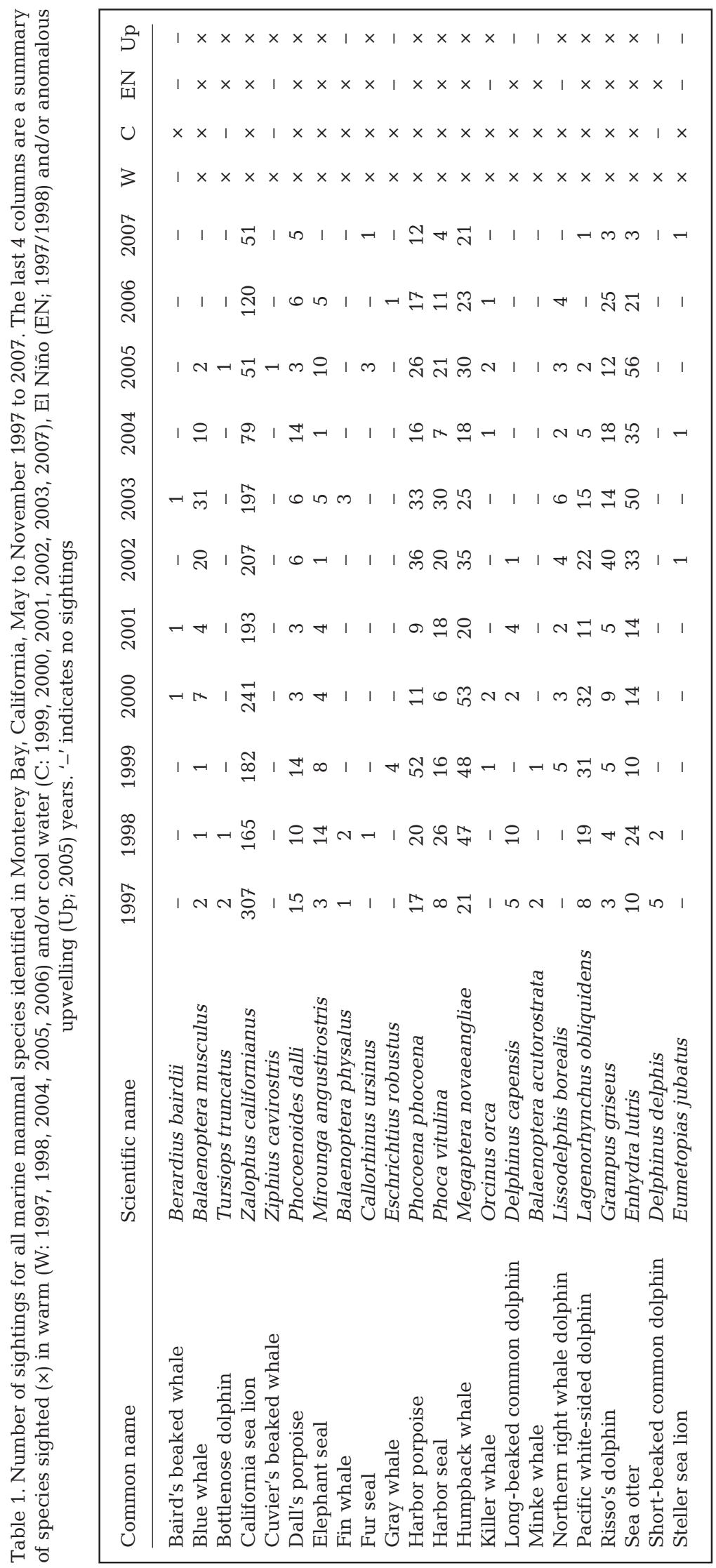

species composition, was examined using a binary similarity index, the Jaccard Index $\left(S_{\mathrm{j}}\right)$. The Jaccard index uses presence/ absence data to determine the similarity between 2 samples, making it possible to include rare species (those without density estimates) in analyses. The range of possible Jaccard coefficients is from 0 (no similarity) to 1 (complete similarity); however, sample size and species richness can affect the maximum value of the coefficient (Wolda 1981).

\section{Statistical analyses}

Randomization tests (10000 iterations) were performed, using Resampling Stats software (version 6, build 1, Resampling Stats, Inc.), to determine whether species richness, species evenness, mean (focal species) density, and individual species densities differed between cool and warm water years. Randomization tests were used rather than a parametric test (such as a $t$-test) to avoid violating the assumption of a normal error distribution and because $t$-tests are less robust with smaller sample sizes. Density and diversity estimates were considered to be significantly different if the observed mean difference was $>95 \%$ of the randomized distribution. One analysis included all years surveyed $(\mathrm{n}=11)$ and another included only the most disparate years $(\mathrm{n}=8$; 1997, 2000, and 2003 were excluded). Because 15 statistical comparisons were performed, we conducted a Benjamini-Hochberg false discover rate test (Benjamini \& Hochberg 1995) using R software (R Development Core Team 2011) to control for the expected proportion of type I errors.

\section{RESULTS}

\section{Density model selection}

We identified 22 species of marine mammals during the 11-yr study (Table 1). MCDS results are presented for the 10 species with enough sightings $(n>55)$ to obtain density estimates (Table 2, Fig. 3). MCDS results also are presented for common dolphin and northern right whale dolphin from 


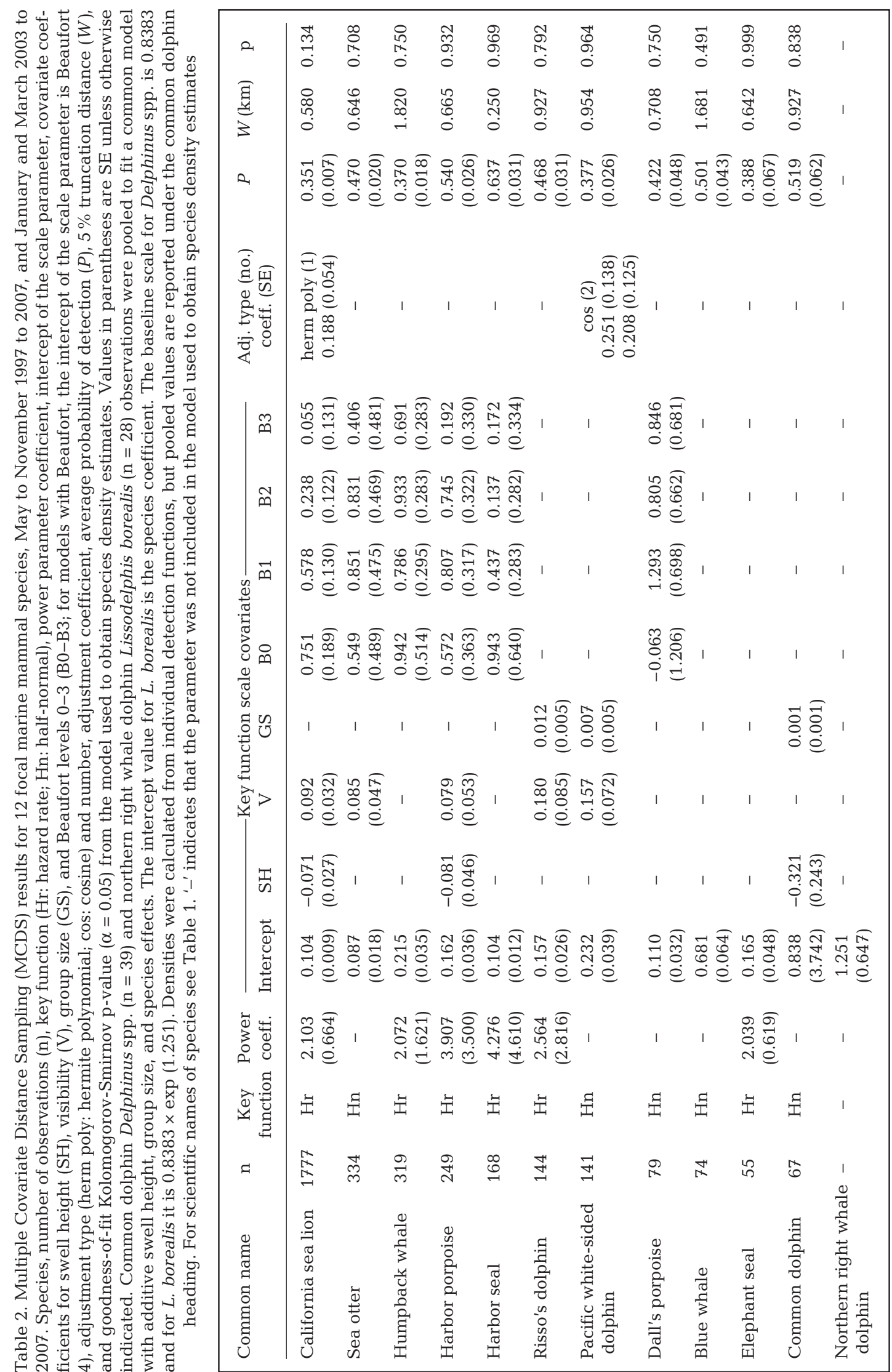



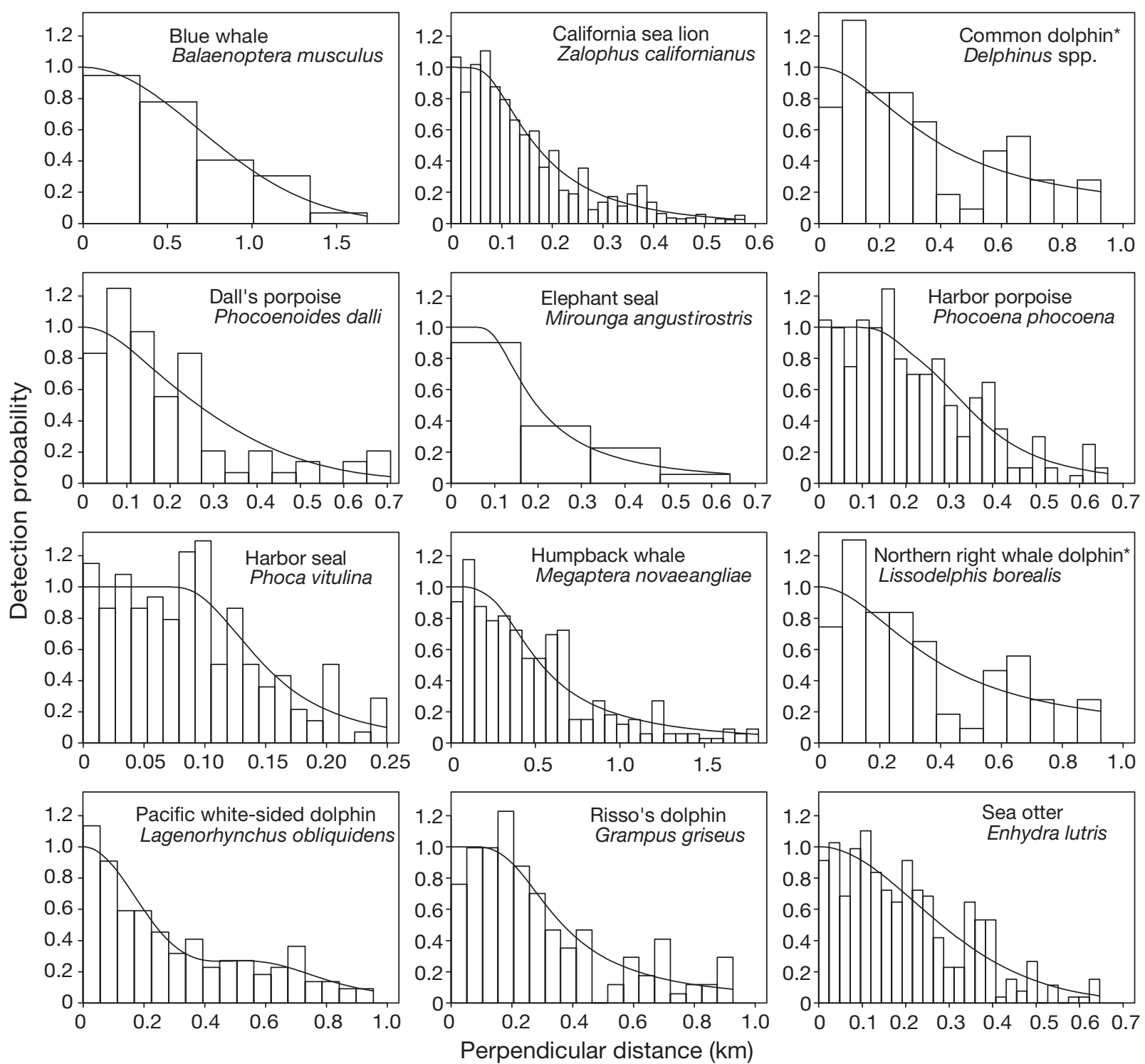

Fig. 3. Observed perpendicular distance $(\mathrm{km})$ with fitted detection functions for 12 focal marine mammal species. Note different scales on $x$-axes. ${ }^{*}$ Common dolphin and northern right whale dolphin histograms are the same because a shared model was used

a shared model with additive swell height, group size, and species effects (Table 2, Fig. 3). The best models chosen for California sea lion, elephant seal Mirounga angustirostris, harbor porpoise, humpback whale, and sea otter were those that minimized AIC. The best models chosen for the remaining species excluded models with the lesser AIC if those models violated assumptions or produced unexpected results. For example, models with numeric covariates with a coefficient counter to expectation were disregarded and the next best model was chosen. Thus models with a positive swell height coefficient (for harbor seal) or negative visibility coefficients (for
Dall's porpoise and common dolphin-northern right whale dolphin) were not selected. The swell height coefficient should have been negative because as swell height increased, the distance at which we could detect individuals or groups should have decreased. Similarly, the visibility coefficient should have been positive because as visibility increased, the distance at which we could detect individuals or groups should also have increased. Coefficients with a sign opposite of expectation likely occurred by chance alone, resulting from unequal sample size distribution across all levels of a covariate. Adjustment terms were not included in the final model for 
Risso's dolphin density because the probability of detection at zero distance with a simple polynomial adjustment was $>1$, violating the assumption of certain detection on the trackline. The best half-normal model was chosen over hazard-rate models for Pacific white-sided dolphin and Dall's porpoise to avoid fitting the spike in sightings at zero distance, likely because of responsive movement of these species towards vessels (Williams \& Thomas 2007). The model minimizing AIC for blue whale included Beaufort coefficients that did not increase from Beaufort 4 to Beaufort 0 as was expected (i.e. this model did not reflect the fact that we were able to detect individu- als or groups at further distances in lesser Beaufort sea states), thus the next best model was chosen. Beaufort coefficients mostly were positive, changing the scale of the detection function and increasing the distance at which objects could be detected.

\section{Annual density and diversity}

Densities of the 12 focal species varied among years (Fig. 4), although mean species richness remained relatively constant (mean \pm SE: $13.7 \pm$ 0.396 species $\mathrm{yr}^{-1}$; Fig. 5). California sea lions, Dall's
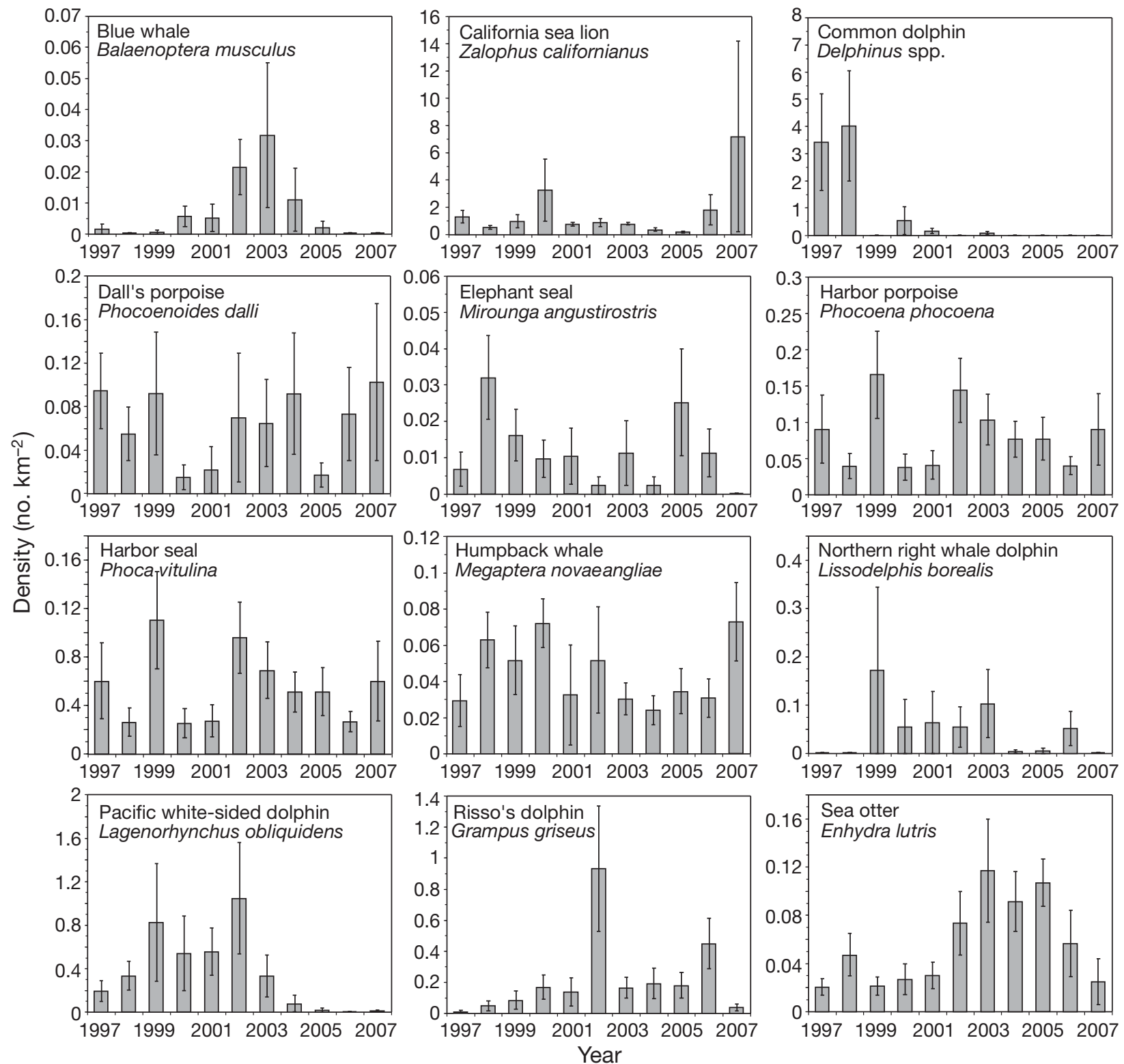

Fig. 4. Annual densities (mean \pm SE) for 12 focal marine mammal species identified in Monterey Bay, California, May to November 1997 to 2007 . Note different scales on $y$-axes 
porpoises, harbor porpoises, harbor seals, humpback whales, Risso's dolphins, and sea otters were sighted every year, and elephant seals were sighted every year but 2007 (Fig. 4). Northern right whale dolphins were absent in 1997, 1998, and 2007, and present in greatest densities during 1999 (Fig. 4). Pacific whitesided dolphins were present in greatest densities from 1999 to 2002, and decreased densities during 1997 , 1998, and 2003 to 2007 (Fig. 4). Common dolphins were present in greatest densities and were the most abundant species of marine mammal during 1997 and 1998, but were sighted infrequently or absent in subsequent years (Fig. 4). Blue whales were present
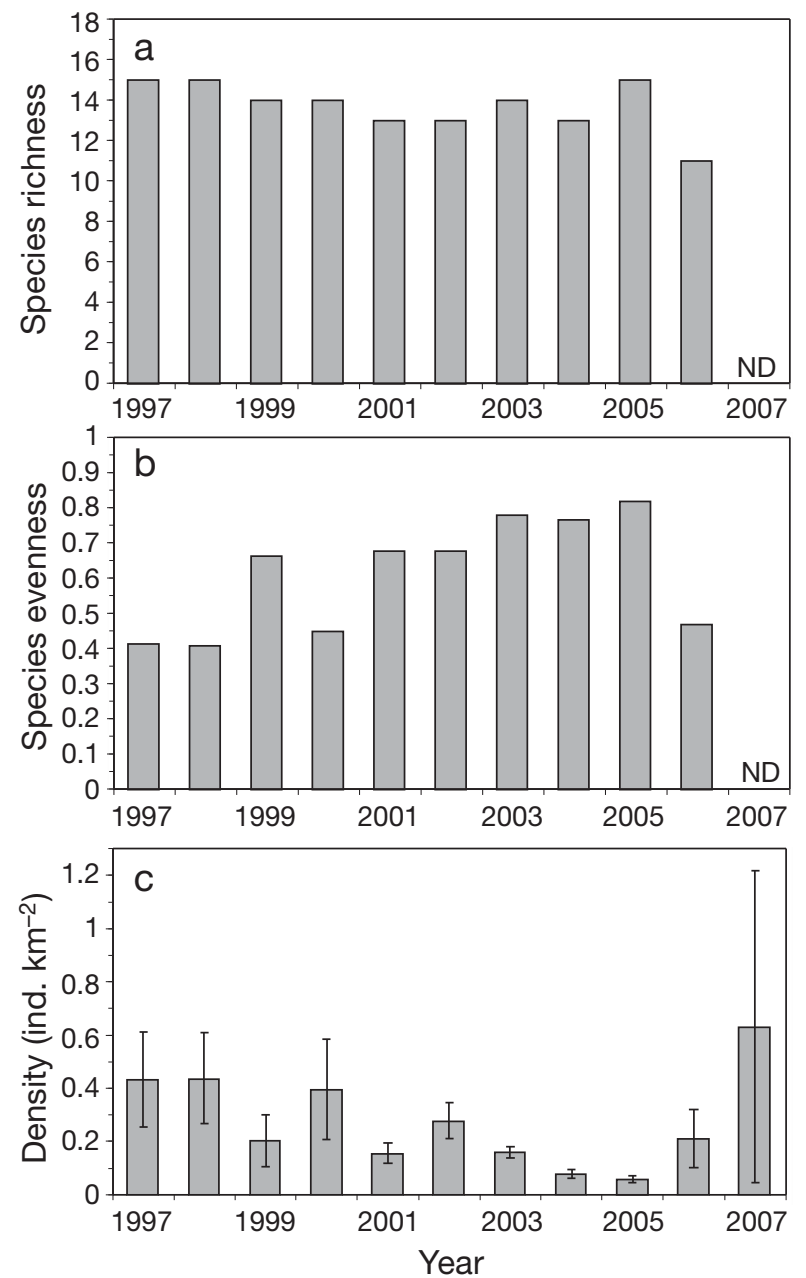

Fig. 5. (a) Species richness, (b) species evenness, and (c) mean density for marine mammal species identified in Monterey Bay, California, May to November 1997 to 2007. Species richness was determined for all species sighted, including rare ones, whereas species evenness (Shannon's equitability index) and density (mean \pm SE) were determined for only the 12 focal species. Species richness and evenness were not calculated for 2007 because of reduced effort that year (ND: no data) in greatest densities during 2003 and in least densities or absent from 1997 to 1999 and 2005 to 2007 (Fig. 4). Risso's dolphins were present in decreased densities during 1997 and 1998, but were almost 10 times as dense during 2002 (Fig. 4). Species richness varied by only 4 species during the 10-yr period, and was 15 (greatest richness observed) during 1997, 1998, and 2005 (Fig. 5). Marine mammals were most evenly distributed, but least dense during 2005, and least even, but dense during 1997 and 1998 (Fig. 5). The greatest density of focal species occurred during 1997, 1998, and 2007 (Fig. 5).

\section{Warm vs. cool years}

Species richness, species evenness, and mean focal species density did not differ significantly between warm and cool years (Table 3). Most species were sighted during at least 1 warm and 1 cool water year (Table 1). The community composition of marine mammals was more similar between warm and cool years $\left(S_{\mathrm{j}}=0.818\right)$ than it was between El Niño and anomalous upwelling years $\left(S_{\mathrm{j}}=0.579\right.$ for a community comparison between 1997/1998 and 2005). No species had significantly greater densities during cool or warm water years; however, Pacific whitesided dolphins and northern right whale dolphins had near significantly greater densities in cool years (Table 3). Performing the same analyses using only the 8 most disparate years (used to develop the discriminate function) did not yield significant results (results not shown).

\section{DISCUSSION}

Marine mammals are wide-ranging predators that respond to environmental conditions over a large spatial area. Monterey Bay is a small region within the larger California Current, which is a temporally and spatially dynamic system. Temporal environmental variability between 1997 and 2007 was most extreme during the 1997/1998 El Niño and 2005 anomalous upwelling events. Although 1997, 1998, and 2005 were all categorized as warm years (in our analyses for Monterey Bay and in CalCOFI reports), the community response of marine mammals differed between the 1997/1998 El Niño and 2005 anomalous upwelling events. These differences most likely resulted from the disparate spatial scales at which El Niño and upwelling occurred. The 1997/1998 El Niño affected the entire Pacific Ocean basin, whereas 
Table 3. Randomization test results (10000 iterations) for differences in species richness, species evenness, focal species density, and individual species densities between warm and cool years. Values presented are means (SE), sample size (n), observed mean difference, and probability of obtaining results that include the observed mean difference with $\mathrm{p}$-values adjusted using the Benjamini-Hochberg false discover rate test (Adj. p). For scientific names of species see Table 1

\begin{tabular}{|c|c|c|c|c|c|c|}
\hline & Warm year mean & $\mathrm{n}$ & Cool year mean & $\mathrm{n}$ & Obs. mean diff. & Adj. $p$ \\
\hline Species richness & $13.800(0.800)$ & 5 & $13.600(0.245)$ & 5 & 0.200 & $1>p>0.694$ \\
\hline Species evenness & $0.575(0.090)$ & 5 & $0.650(0.054)$ & 5 & 0.075 & $0.743>p>0.664$ \\
\hline Density (focal species) & $0.244(0.076)$ & 5 & $0.305(0.089)$ & 6 & 0.061 & $0.743>p>0.664$ \\
\hline Blue whale & $0.003(0.0002)$ & 5 & $0.011(0.005)$ & 6 & 0.008 & $0.585>\mathrm{p}>0.399$ \\
\hline California sea lion & $0.821(0.309)$ & 5 & $2.298(1.056)$ & 6 & 1.477 & $0.609>p>0.399$ \\
\hline Common dolphin & $1.489(0.917)$ & 5 & $0.129(0.086)$ & 6 & 1.360 & $0.510>p>0.280$ \\
\hline Dall's porpoise & $0.066(0.014)$ & 5 & $0.061(0.015)$ & 6 & 0.005 & $0.935>p>0.694$ \\
\hline Elephant seal & $0.016(0.006)$ & 5 & $0.008(0.002)$ & 6 & 0.007 & $0.585>\mathrm{p}>0.399$ \\
\hline Harbor porpoise & $0.065(0.011)$ & 5 & $0.097(0.021)$ & 6 & 0.032 & $0.585>p>0.399$ \\
\hline Harbor seal & $0.055(0.015)$ & 5 & $0.065(0.012)$ & 6 & 0.010 & $0.743>p>0.664$ \\
\hline Humpback whale & $0.037(0.007)$ & 5 & $0.052(0.008)$ & 6 & 0.016 & $0.585>\mathrm{p}>0.383$ \\
\hline Northern right whale dolphin & $0.012(0.010)$ & 5 & $0.075(0.024)$ & 6 & 0.063 & $0.150>p>0.105$ \\
\hline Pacific white-sided dolphin & $0.126(0.062)$ & 5 & $0.553(0.149)$ & 6 & 0.427 & $0.203>p>0.105$ \\
\hline Risso's dolphin & $0.177(0.077)$ & 5 & $0.255(0.137)$ & 6 & 0.079 & $0.901>\mathrm{p}>0.694$ \\
\hline Sea otter & $0.065(0.016)$ & 5 & $0.049(0.016)$ & 6 & 0.016 & $0.743>p>0.610$ \\
\hline
\end{tabular}

anomalous upwelling was more localized off the west coast of North America. Thus it is important to consider the physical factors leading to anomalous oceanographic events to understand and predict how marine mammals will respond to environmental variability.

\section{Focal species density}

The lack of statistically significant differences in mean focal species density between warm and cool years likely occurred because individual and community responses of marine mammals differed between the 1997/1998 El Niño and the 2005 anomalous upwelling events. During 2005, the delayed onset of upwelling resulted in warmer than average spring and summer SSTs, decreased primary production and zooplankton abundance (Mackas et al. 2006, Schwing et al. 2006, Barth et al. 2007), and reduced catches of mid-trophic-level fish species (Brodeur et al. 2006) off the west coast of North America. Although the annual UI value for 2005 was not extremely low, it was the delayed onset of upwelling that had substantial impacts on the ecosystem. The biological effects of the anomalous oceanic conditions of 2005 were limited to central California through southern British Columbia (northern California Current; Brodeur et al. 2006, Mackas et al. 2006, Sydeman et al. 2006) and positive zooplankton anomalies were documented from Point Conception, California, south to Baja, Mexico (southern California
Current; Mackas et al. 2006). Thus, it is possible that decreased density of marine mammal species in Monterey Bay during 2005 resulted from the redistribution of more mobile species to areas outside the region affected by the upwelling anomaly. Indeed, densities of wider-ranging, more seasonally abundant species (e.g. blue whales, Dall's porpoises, and Pacific white-sided dolphins) decreased in Monterey Bay during 2005, whereas densities of resident species (e.g. California sea lions, harbor porpoises, harbor seals, and sea otters) remained similar to or increased from the previous year (point estimates only).

Increased densities of marine mammals in Monterey Bay during the 1997/1998 El Niño can be attributed to the marked increased density of common dolphins during those years, in addition to the aggregation of cetacean species in narrow nearshore areas of increased productivity, such as Monterey Bay (Benson et al. 2002). Although productivity was reduced in Monterey Bay during the 1997/1998 El Niño event compared with other years, there was still sufficient nutrient availability nearshore to support some primary production (Kudela \& Chavez 2000, Chavez et al. 2002). Therefore, during basin-wide decreases in productivity (e.g. El Niño events), mobile top predators may be more likely to move from offshore to nearshore areas and less likely to redistribute north-south, to the extent that may have occurred during the anomalous upwelling conditions.

Given the response of marine mammals to the basin-wide 1997/1998 El Niño event, it is possible that marine mammals in the California Current will 
respond to global warming in a similar manner. Thus increased density and decreased species evenness may occur in Monterey Bay as Earth's climate changes. Large groups of typically warm-waterassociated species may move into Monterey Bay and aggregate nearshore where productivity is greater, increasing predation pressure on mid-trophic-level species that may already be stressed from other climate change-related factors.

\section{Diversity}

The lack of statistically significant differences in species evenness between warm and cool years is supported by Jaccard similarity results, which indicate that the community composition of marine mammals was more similar between warm and cool years than it was between the warm years of the 1997/1998 El Niño and the 2005 anomalous upwelling events.

The lack of a statistically significant difference in species richness between warm and cool years and the similarity of species richness among all years are indications that species richness may not be the appropriate measure of diversity for this study. Species richness did not vary much among years because the presence of regularly occurring species and different rare species totaled approximately the same richness every year. Therefore, despite changes in the species composition among years, the total number of species sighted was similar for all years. Additionally, both evenness and Jaccard similarity results indicated that there were differences in species composition between 1997/1998 and 2005, whereas species richness was identical in all 3 years. Therefore a measure of species composition, rather than species richness, may provide more insight into marine mammal diversity patterns for future studies.

\section{Individual species densities}

Although there were no statistically significant differences in the densities of individual species during cool or warm years, the greater (near significant) densities of Pacific-white sided dolphins and northern right whale dolphins in Monterey Bay during cool years may have biological significance. These 2 cold-temperate species likely moved south with cool waters during years dominated by cool conditions. Barlow \& Forney (2007) found similar increased abundances of these species in waters off California during the cool-water year of 1996, but reported no consistent variation in the abundance of Risso's or common dolphins with warm or cool water years. We also found no significant differences in the densities of Risso's or common dolphins during warm years and attribute this result to the fact that these species did not respond consistently to similarly grouped years. The conspicuous increase in common dolphin densities reported in this study during the 1997/1998 El Niño event did not occur again in subsequent warm years (during 2004, 2005, and 2006 no common dolphins were sighted). It is possible that during the 1997/1998 El Niño event, large groups of common dolphins moved north or inshore into Monterey Bay in search of prey, whereas during 2004, 2005, and 2006 common dolphins remained in their normal habitat further south (southern California to Mexico) or offshore because those areas were largely unaffected by the upwelling anomalies along the coast (Peterson et al. 2006).

We expected our results would differ slightly from those of Barlow \& Forney (2007) because they sampled a much larger region of the California Current at a coarser spatial (including waters off California, Oregon, and Washington) and temporal scale. However, when our results are similar, it may be a good indication of the extent and conditions under which Monterey Bay can be used as an indicator of the larger California Current System. For example, during cool-water years, increased abundances of Pacific white-sided dolphins and northern right whale dolphins in Monterey Bay may indicate increased abundances of these species throughout the California Current. However, Barlow \& Forney (2007) found increased abundances of Dall's porpoise in the California Current during cool-water years and we did not find a similar increase in Monterey Bay. Both our study and that of Barlow \& Forney (2007) found decreased abundances of blue whales in 2005 and attribute this decrease to a redistribution of individuals outside of the study region. Thus, Monterey Bay may act as an indicator of the larger California Current for some cool-water associated species, but results are not consistent across species.

Marine mammals respond not only to environmental variability, but also to the distribution of their prey, which responds to oceanographic conditions. Marine mammals typically move to areas where prey is more abundant. For example, densities of Risso's dolphins (which feed almost exclusively on squid) increased conspicuously in Monterey Bay during 2002, concurrent with a marked increase in abundance of Humboldt squid Dosidicus gigas (Zeid- 
berg \& Robison 2007). Additionally, the market squid (Loligo opalescens) fishery in Monterey Bay during 2002 had a near-unprecedented record-setting year (CDFG 2003). Thus the increase in Risso's dolphin density in Monterey Bay during 2002 may have been a direct result of increased squid availability that year, and squid (as with other prey) are extremely responsive to changes in environmental conditions (Jackson \& Domeier 2003, Zeidberg et al. 2006).

\section{Summary and conclusions}

By tracking a community of top predators in Monterey Bay during an 11-yr period, we examined interannual changes in marine mammal density and diversity as related to temporal environmental variability. We found no statistically significant differences in density and diversity when comparing warm and cool water years, likely a result of the large amount of variability in the system. However, the long-term nature of the study enabled us to document the response of marine mammals to both local (2005 anomalous upwelling) and basin-wide (1997/1998 El Niño) events. We found that marine mammals responded differently to these warm-water years depending on the mechanism initiating the variability. During basin-wide decreases in productivity (e.g. El Niño events), mobile top predators may be more likely to move from offshore to nearshore areas and aggregate in regions with relatively greater productivity, whereas during more localized decreases in productivity (e.g. anomalous upwelling), marine mammals may redistribute to regions north and south of the area affected by the anomalous conditions. Climate change may affect marine mammals in a similar manner as the 1997/1998 El Nino event, and lead to increased densities of marine mammals in Monterey Bay as the oceans continue to warm. A better understanding of the specific processes that induce warm and cool water years will provide additional insight into the response of marine mammals to future environmental variability.

Acknowledgements. We thank L. Bradford, the crew of the RV 'John H. Martin', and the more than 200 volunteer observers who assisted with data collection for the Wind to Whale project. R. Holland, A. Jackson, S. Bros-Seemann, and J. Laake assisted with data management and statistical analyses. Funding was provided by the Center for Integrated Marine Technologies (CIMT) and the Monterey Bay National Marine Sanctuary (MBNMS). Additional support was granted to J.A.B. from the American Cetacean Society Monterey Bay Chapter, the Marine Technology Society, the
David and Lucile Packard Research and Travel Award, the Myers Oceanographic and Marine Biology Trust, and San José State University. We are grateful to L. Ballance and three anonymous reviewers for improving this manuscript.

\section{LITERATURE CITED}

Akaike H (1973) Information theory and an extension of the maximum likelihood principle. In: Petran BN, Csaaki F (eds) Second International Symposium on Information Theory. Akadeemiai Kiadi, Budapest, p 267-281

Barber RT, Chavez FP (1983) Biological consequences of El Niño. Science 222:1203-1210

Barber RT, Smith RL (1981) Coastal upwelling ecosystems. In: Longhurst AR (ed) Analysis of marine ecosystems. Academic Press, New York, NY, p 31-68

Barlow J, Forney KA (2007) Abundance and population density of cetaceans in the California Current ecosystem. Fish Bull 105:509-526

Barth JA, Menge BA, Lubchenco J, Chan F and others (2007) Delayed upwelling alters nearshore coastal ocean ecosystems in the northern California current. Proc Natl Acad Sci USA 104:3719-3724

Beaugrand G, Reid PC, Ibanez F, Lindley JA, Edwards M (2002) Reorganization of North Atlantic marine copepod biodiversity and climate. Science 296:1692-1694

Benjamini Y, Hochberg Y (1995) Controlling the false discovery rate: a practical and powerful approach to multiple testing. J R Stat Soc B 57:289-300

Benson SR, Croll DA, Marinovic BB, Chavez FP, Harvey JT (2002) Changes in the cetacean assemblage of a coastal upwelling ecosystem during El Niño 1997-98 and La Niña 1999. Prog Oceanogr 54:279-291

Bograd SJ, Schroeder I, Sarkar N, Qui X, Sydeman WJ, Schwing FB (2009) Phenology of coastal upwelling in the California Current. Geophys Res Lett 36:L01602 doi: 10.1029/2008GL035933

> Brodeur RD, Ralston S, Emmett RL, Trudel M, Auth TD, Phillips AJ (2006) Anomalous pelagic nekton abundance, distribution, and apparent recruitment in the northern California Current in 2004 and 2005. Geophys Res Lett 33:L22S08 doi:10.1029/2006GL026614

Buckland ST, Anderson DR, Burnham KP, Laake JL, Borchers DL, Thomas L (2001) Introduction to distance sampling: estimating abundance of biological populations. Oxford University Press, New York, NY

Buckland ST, Anderson DR, Burnham KP, Laake JL, Borchers DL, Thomas L (2004) Advanced distance sampling: estimating abundance of biological populations. Oxford University Press, New York, NY

Burtenshaw JC, Oleson EM, Hildebrand JA, McDonald MA, Andrew RK, Howe BM, Mercer JA (2004) Acoustic and satellite remote sensing of blue whale seasonality and habitat in the Northeast Pacific. Deep-Sea Res II 51: 967-986

Carr ME, Kearns EJ (2003) Production regimes in four Eastern Boundary Current systems. Deep-Sea Res II 50: 3199-3221

CDFG (California Department of Fish and Game) (2003) Review of some California fisheries for 2002: market squid, sea urchin, Dungeness crab, prawn, coastal pelagic finfish, albacore, ocean salmon, nearshore livefish, Pacific herring, and recreational. Calif Coop Ocean 
Fish Invest Rep 44:10-27

Chavez FP (1996) Forcing and biological impact of onset of the 1992 El Niño in central California. Geophys Res Lett 23:265-268

> Chavez FP, Pennington JT, Castro CG, Ryan JP and others (2002) Biological and chemical consequences of the 1997-1998 El Niño in central California waters. Prog Oceanogr 54:205-232

Croll DA, Marinovic B, Benson S, Chavez FP, Black N, Ternullo R, Tershy BR (2005) From wind to whales: trophic links in a coastal upwelling system. Mar Ecol Prog Ser 289:117-130

- Forney K, Barlow J (1998) Seasonal patterns in the abundance and distribution of California cetaceans, 19911992. Mar Mamm Sci 14:460-489

Friedlaender AS, Halpin PN, Qian SS, Lawson GL, Wiebe $\mathrm{PH}$, Thiele D, Read AJ (2006) Whale distribution in relation to prey abundance and oceanographic processes in shelf waters of the Western Antarctic Peninsula. Mar Ecol Prog Ser 317:297-310

Glantz MH, Thompson JD (eds) (1981) Resource management and environmental uncertainty, John Wiley \& Sons, New York, NY

Greene HG, Maher NM, Paull CK (2002) Physiography of the Monterey Bay National Marine Sanctuary and implications about continental margin development. Mar Geol 181:55-82

Hayward TL (1993) Preliminary observations of the 19911992 El Niño in the California Current. Calif Coop Ocean Fish Invest Rep 34:21-29

> Hickey BM (1979) The California Current Systemhypotheses and facts. Prog Oceanogr 8:191-279

- Hillebrand H (2004) On the generality of the latitudinal diversity gradient. Am Nat 163:192-211

Holland R (2008) SeeBird_WinCruz: a data entry program for strip transect data for seabirds and marine mammals. Southwest Fisheries Science Center, NOAA Fisheries, La Jolla, CA

Hooff RC, Peterson WT (2006) Copepod biodiversity as an indicator of changes in ocean and climate conditions of the northern California current ecosystem. Limnol Oceanogr 51:2607-2620

Hughes L (2000) Biological consequences of global warming: is the signal already apparent? Trends Ecol Evol 15: $56-61$

Hutchings L, Pitcher GC, Probyn TA, Bailey GW (1995) The chemical and biological consequences of coastal upwelling. In: Summerhayes CP, Emeis K-C, Angel MV, Smith RL, Zeitzschel B (eds) Upwelling in the ocean: modern processes and ancient records. John Wiley \& Sons, New York, p. 65-81

Huyer A (1983) Coastal upwelling in the California Current System. Prog Oceanogr 12:259-284

Hyrenbach KD, Veit RR (2003) Ocean warming and seabird communities of the southern California Current System (1987-98): response at multiple temporal scales. DeepSea Res II 50:2537-2565

Jackson GD, Domeier ML (2003) The effects of an extraordinary El Niño / La Niña event on the size and growth of the squid Loligo opalescens off Southern California. Mar Biol 142:925-935

Keiper CA, Ainley DG, Allen SG, Harvey JT (2005) Marine mammal occurrence and ocean climate off central California, 1986 to 1994 and 1997 to 1999. Mar Ecol Prog Ser 289:285-306
Kudela RM, Chavez FP (2000) Modeling the impact of the 1992 El Niño on new production in Monterey Bay, California. Deep-Sea Res Part II 47:1055-1076

Lenarz WH, Ventresca DA, Graham WM, Schwing FB, Chavez F (1995) Explorations of El Niño events and associated biological population dynamics off central California. Calif Coop Ocean Fish Invest Rep 36:106-119

- Lerczak JA, Hobbs RC (1998) Calculating sighting distances from angular readings during shipboard, aerial, and shore-based marine mammal surveys. Mar Mamm Sci 14:590-599

Lowry MS, Forney KA (2005) Abundance and distribution of California sea lions (Zalophus californianus) in central and northern California during 1998 and summer 1999. Fish Bull 103:331-343

Mackas DL, Peterson WT, Ohman MD, Lavaniegos BE (2006) Zooplankton anomalies in the California Current system before and during the warm ocean conditions of 2005. Geophys Res Lett 33:L22S07 doi:10.1029/2006 GL027930

Marinovic BB, Croll DA, Gong N, Benson SR, Chavez FP (2002) Effects of the 1997-1999 El Niño and La Niña events on zooplankton abundance and euphausiid community composition within the Monterey Bay coastal upwelling system. Prog Oceanogr 54:265-277

Pennington JT, Chavez FP (2000) Seasonal fluctuations of temperature, salinity, nitrate, chlorophyll and primary production at station H3/M1 over 1989-1996 in Monterey Bay, California. Deep-Sea Res II 47:947-973

Peterson B, Emmett R, Goericke R, Venrick E and others (2006) The state of the California Current, 2005-2006: Warm in the north, cool in the south. Calif Coop Ocean Fish Invest Rep 47:30-74

R Development Core Team (2011) R: A language and environment for statistical computing, version 2.14.0. R Foundation for Statistical Computing, Vienna, Austria. ISBN 3-900051-07-0, URL www.R-project.org

> Rohde K (1992) Latitudinal gradients in species diversity: the search for the primary cause. Oikos 65:514-527

> Rosenfeld LK, Schwing FB, Garfield N, Tracy DE (1994) Bifurcated flow from an upwelling center: a cold water source for Monterey Bay. Cont Shelf Res 14:931-964

Schwing FB, Bond NA, Bograd SJ, Mitchell T, Alexander MA, Mantua N (2006) Delayed coastal upwelling along the U.S. West Coast in 2005: A historical perspective. Geophys Res Lett 33:L22S01 doi:10.1029/2006GL026911

Send U, Beardsley RC, Clinton DW (1987) Relaxation from upwelling in the coastal ocean dynamics experiment. J Geophys Res C 92:1683-1698

> Service SK, Rice JA, Chavez FP (1998) Relationship between physical and biological variables during the upwelling period in Monterey Bay, CA. Deep-Sea Res II 45: 1669-1685

Shepard FP (1973) Submarine geology. Harper \& Row, New York, NY

> Skogsberg T (1936) Hydrography of Monterey Bay, California. Thermal conditions, 1929-1933. Trans Am Philos Soc 29:1-152

Skogsberg T, Phelps A (1946) Hydrography of Monterey Bay, California. Thermal conditions, Part II, 1934-1937. Proc Am Philos Soc 90:350-386

Snyder MA, Sloan LC, Diffenbaugh NS, Bell JL (2003) Future climate change and upwelling in the California Current. Geophys Res Lett 30:1823 doi:10.1029/ 2003GL017647 
Sydeman WJ, Allen SG (1999) Pinniped population dynamics in central California: Correlations with sea surface temperature and upwelling indices. Mar Mamm Sci 15: 446-461

Sydeman WJ, Bradley RW, Warzybok P, Abraham CL and others (2006) Planktivorous auklet Ptychoramphus aleuticus responses to ocean climate, 2005: unusual atmospheric blocking? Geophys Res Lett 33:L22S09 doi: 10.1029/2006GL026736

Thomas L, Laake JL, Strindberg S, Marques FFC and others (2006) Distance 5.0. Release 2. Research Unit for Wildlife Population Assessment, University of St. Andrews, UK, available at www.ruwpa.st-and.ac.uk/distance/

Trathan PN, Forcada J, Murphy EJ (2007) Environmental forcing and Southern Ocean marine predator populations: effects of climate change and variability. Philos Trans R Soc Lond B 362:2351-2365

Weise MJ, Costa DP, Kudela RM (2006) Movement and diving behavior of male California sea lions (Zalophus californianus) during anomalous oceanographic conditions of 2005 compared to those of 2004. Geophys Res Lett 33: L22S10 doi:10.1029/2006GL027113

Whitehead H, McGill B, Worm B (2008) Diversity of deepwater cetaceans in relation to temperature: implications

Editorial responsibility: Steve Dawson,

Dunedin, New Zealand for ocean warming. Ecol Lett 11:1198-1207

- Whitehead H, O'Brien K, Worm B (2010) Diversity of deepwater cetaceans and primary productivity. Mar Ecol Prog Ser 408:1-5

Williams R, Thomas L (2007) Distribution and abundance of marine mammals in coastal waters of British Columbia, Canada. J Cetacean Res Manag 9:15-28

Wolda H (1981) Similarity indices, sample size and diversity. Oecologia 50:296-302

Woodd-Walker RS, Ward P, Clarke A (2002) Large-scale patterns in diversity and community structure of surface water copepods from the Atlantic Ocean. Mar Ecol Prog Ser 236:189-203

Worm B, Sandow M, Oschlies A, Lotze HK, Myers RA (2005) Global patterns of predator diversity in the open oceans. Science 309:1365-1369

Zeidberg LD, Robison BH (2007) Invasive range expansion by the Humboldt squid, Dosidicus gigas, in the eastern North Pacific. Proc Natl Acad Sci USA 104: 12948-12950

Zeidberg LD, Hamner WM, Nezlin NP, Henry A (2006) The fishery for California market squid (Loligo opalescens) (Cephalopoda: Myopsida), from 1981 through 2003. Fish Bull 104:46-59

Submitted: April 7, 2011; Accepted: March 8, 2012 Proofs received from author(s): June 22, 2012 